\title{
Culturally and linguistically diverse students in health professional programs: An exploration of concerns and needs
}

\author{
Conor Gilligan, Sue Outram \\ Faculty of Health, School of Medicine and Public Health, Priority Research Centre for Health Behaviour, University of Newcastle, \\ Newcastle, Australia
}

\begin{abstract}
Introduction: Cultural diversity amongst students in tertiary institutions in Australia and globally has increased rapidly in the last decade, and is continuing to do so. Methods: Focus groups were held at the University of Newcastle, NSW to: (1) examine the specific needs of international students in the Master of Pharmacy, Bachelor of Medicine, and Bachelor of Nursing programs in relation to language and cultural considerations and (2) understand the attitudes of domestic students to the cultural issues faced among their peers. The project explored these issues with the intention to inform curricula changes to accommodate the needs of Culturally and Linguistically Diverse (CALD) students. Results: The key themes emerging from international students were: difficulties in spoken

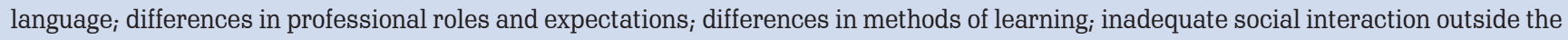
classroom $_{i}$ and acceptance of differences in cultural and religious practices. The domestic student views reinforced the comments from international students both in regard to social interaction and participation in class discussions. Although local students were interested in learning from international students about culture and religious beliefs, there were limited initiatives from both sides. Discussion: There is a need for tertiary institutions that benefit economically from increasing numbers of international students to help them to study and live in a new environment. Assistance needs to go beyond learning the English language to helping students understand its use in a professional context (health terminology and slang used by patients), the nuances of the health professional disciplines in a western society, the approach to study and problem-based learning styles, and skills to assist with social interaction. The results of the present exploration have led to a series of proposed actions for the University of Newcastle. These recommendations are applicable to any "Western" teaching institution with a large number of international students from developing countries enrolled in their health programs.
\end{abstract}

Keywords: Culturally and linguistically diverse, international, language, medicine, nursing, pharmacy

\section{Introduction}

As in many countries globally, cultural diversity amongst students in Australian tertiary institutions has increased rapidly in the last decade, and is continuing to do so. In 2010 , over 200,000 international students were enrolled

\begin{tabular}{|l|l|}
\hline \multicolumn{2}{|c|}{ Access this article online } \\
\hline \begin{tabular}{l} 
Quick Response Code: \\
\hline \multirow{2}{*}{}
\end{tabular} & $\begin{array}{l}\text { Website: } \\
\text { www.educationforhealth.in }\end{array}$ \\
\cline { 2 - 2 } & $\begin{array}{l}\text { DOI: } \\
\star \star \star \star \star \star\end{array}$ \\
\hline
\end{tabular}

in Australian tertiary institutions, with growth rapidly progressing toward $20 \%$ of total student enrolments. ${ }^{[1]}$ In the United States, in 2009/10, there was a 30\% increase in the number of Chinese students enrolled in tertiary study. ${ }^{[2]}$ In the UK, international students make up $16 \%$ of total tertiary enrolments. ${ }^{[3]} \mathrm{A}$ substantial proportion of Australia's medical workforce is overseas born. By the mid-1990s, 40\% of students enrolled in Australian medical courses were overseas born, with $24 \%$ of these born in Asian countries. ${ }^{[4]}$ Growth in international student numbers is recognized as beneficial not only economically, but in terms of Australia's engagement with the region, knowledge sharing, and preparation of the workforce for the global environment. ${ }^{[5]}$ In this context, it is recognized that diversity in the student cohort can also be beneficial for domestic students in terms of increasing cultural

\section{Address for correspondence:}

Dr. Conor Gilligan, Discipline of Health Behaviour Sciences, University of Newcastle, Level W4, Desk 038, HMRI Building, Lot 1 Kookaburra Circuit New Lambton Heights 2305. E-mail: Conor.Gilligan@newcastle.edu.au 
awareness and achieving cultural competency goals. ${ }^{[5]}$

A study of medical graduates in the USA reported that Caucasian students exposed to high levels of racial and ethnic diversity in their student cohorts were more likely to rate themselves as highly prepared to care for minority populations, and expressed strong attitudes endorsing equitable access to care. These associations were highest in medical schools in which students perceived positive climates for interracial interaction. ${ }^{[6]}$

It is important to ensure an equitable learning experience for these increasing numbers of international students. In the USA and Canada, recognition of the role of diversity among healthcare professionals in achieving equitable care for a diverse patient population has led to a series of efforts to attract and retain students from diverse or minority groups into health programs, in particular Nursing programs. ${ }^{[7-10]}$ Successful approaches include orientation activities, ${ }^{[9]}$ the use of nurse tutors to work with study groups and give particular guidance to students with English as a second language, ${ }^{[10,11]}$ specific social, financial, and language support, development of faculty cultural competence, ${ }^{[9]}$ and changes in a range of curricular and teaching approaches to account for language and cultural considerations. ${ }^{[7]}$

Large international student numbers have brought with them difficulties in terms of quality assurance and social infrastructure, both in education and future employment. ${ }^{[5]}$ English language proficiency has been shown to be directly related to workplace readiness and employment outcomes for international students. ${ }^{[12]}$ Other characteristics, such as diversity of experience and skills and "cultural fit" in the workplace, also appear to impact upon the employability of international students. ${ }^{[12]}$ International students report difficulties not only academically, but socially, with cultural and language barriers impacting upon their capacity to integrate with domestic students. The Australian Government Department of Education, Employment, and Workplace Relations has published a series of examples of good practice in assisting international students to integrate with Australian students and the wider community, which arise from tertiary institutions and colleges throughout Australia. ${ }^{[13]}$ The projects all share common themes of sharing, encouraging group work and support and efforts to include international students in social activities. Many of the projects came about due to feedback from international students themselves, particularly that they were feeling disconnected from their courses, and from other students.

The Master of Pharmacy, Bachelor of Medicine, Joint Medical Program and Bachelor of Nursing programs at the University of Newcastle, NSW, Australia, include substantial cohorts of culturally and linguistically diverse (CALD) students. One of the strategic imperatives of the Faculty of Health is to increase the number of international students to $20 \%$ of total enrolments. In 2009, the Year 1 Pharmacy cohort (91 students) included an increase in international student numbers compared to previous year's 26 students, as well as a substantial number of students who have English as an additional language. Further, 21 international students enrolled in 2010. Similarly in Medicine, 23 of the 2010 Year 1 cohort (148 students) were International students. In Nursing, just over onequarter of undergraduate students are immigrant, refugee, or international students, and for $15 \%$ of students, English is their second language. In 2010, 51 international students enrolled in the Bachelor of Nursing Program.

This poses challenges for teaching in terms of both language and cultural considerations. It is important to ensure that all students receive appropriate education and are given the opportunity to improve their English-speaking skills in a culturally safe environment. The cultural differences and needs of these students must also be considered in relation to their impact upon their practice and their communication with colleagues and patients within the Australian Healthcare system. As well as considering and accommodating the cultural and language needs of these students, it is important to ensure that domestic students are adequately equipped to deal with the needs of their present and future CALD colleagues and patients.

A series of discussions were held to: (1) discover the specific needs of CALD students in the Master of Pharmacy, Joint Medical Program, and Bachelor of Nursing in relation to language and cultural considerations; and (2) delineate the attitudes of domestic students to the cultural issues experienced by their peers and patients. This project explores these issues with the intention to inform curricular changes to accommodate the needs of CALD students.

\section{Methods}

International CALD students in the three programs were invited to take part in focus group discussions. Nursing and medical students were identified through their involvement in courses. International students in the Bachelor of Nursing are required to complete the course "Clinical for International Students" and specialized tutorials are run to assist International students in the Bachelor of Medicine. Domestic students in these programs were invited through convenience sampling of tutorial groups (which are specifically created to capture a range of student demographics). In the Master of Pharmacy, an invitation was sent to all Year 1 students ( $n$ $=91$ ). Students were asked to register and attend one of a series of profession and background-specific sessions offered. Focus groups were continued until theoretical saturation was reached (i.e. no new information was obtained). In total, four 
sessions were held with international students, and two with domestic students. The sessions were held in late 2009 and early 2010. All participants gave informed consent to take part in discussions. The project was approved by the University of Newcastle Human Research Ethics Committee (approval H-2009-0125).

Focus group discussions were semi-structured, using a series of open-ended questions designed to explore the students' experiences in each program (approaches to learning and study), in living in Australia (cultural and language differences), making friends in Australia (social considerations), and any other relevant experiences or concerns they wished to share. CALD students were given the opportunity to attend genderspecific or mixed sessions, but all opted for mixed sessions. Sessions with domestic students covered their experiences with and reactions to the CALD students in their program, as well as their attitudes and knowledge about the cultural considerations necessary in dealing with their peers and future patients. The interview schedule was developed based on themes identified from previous literature including differences in learning styles, ${ }^{[14]}$ use of idioms and slang expressions, isolation, culture shock, ${ }^{[15]}$ and differences in client-health provider cultural expectations. ${ }^{[16]}$ All focus group sessions were facilitated by the researchers (CG and SO), with the facilitator who had the least direct involvement with the particular student cohort selected to run each session. Sessions were audio-recorded, with recordings used to supplement notes taken throughout the discussions. Recordings were not fully transcribed.

Iterative thematic analysis was undertaken by both researchers (CG and SO). The first author prepared notes during and after each focus group, supplemented with direct quotes from a partial transcription of the recording. This enabled the first author to conduct data reduction and preliminary analysis of themes emerging from the data. Discussions were then held with the second author to add any additional points and ensure agreement of the categories and themes. Discussions were held at each iteration of data reduction and analysis as additional focus group results were added. This process was based on the method of thematic analysis presented by Malterud ${ }^{[17]}$ and used effectively, more recently, by Frisch et al. ${ }^{[18]}$

\section{Results}

\section{Participants}

Participants were students who received an invitation to participate and attended a scheduled session. Participants represent approximately 9\% (Pharmacy) to 25\% (Medicine) of the international students in the year-group invited. Approximately $20 \%$ of the international students in their second year of the Nursing program participated. One focus group session was held with Bachelor of Medicine students, two with Bachelor of Nursing students, and two with Master of Pharmacy students. Approximately 90 local students received an invitation to participate and 11 attended one of two separate sessions. Each student participated only once.

The students in each program differed in terms of demographic characteristics [Table 1]. International medical students predominantly originated from Malaysia, through a partnership between the University of Newcastle and two undergraduate colleges in Kuala Lumpur. The Bachelor of Nursing international students differed in that they were older, from a range of countries and religious backgrounds, and most had studied nursing in their home country prior to studying in Australia. The Master of Pharmacy attracts a different group of students, in that being a Masters course, all students have studied previously, and some of the international students are qualified pharmacists or have studied some pharmacy in their countries of origin. Unlike the predominantly Muslim Malaysian medical students, the Malaysian students in this program identified as Buddhist and Christian. Two of the students had obtained their previous degree at the University of Newcastle.

The domestic students came to Newcastle to study from a range of metropolitan (Sydney) and rural areas of New South Wales. The medical students were all in their second year of study in medicine: one had begun studying medicine immediately after leaving school, others had enrolled in various other programs for up to 3 years prior to beginning, and others had taken 1 or 2 years off from study to work. Local Master of Pharmacy students were in the second year of the Pharmacy program and had come to the program either directly from their previous degree, or after several years of working. There were no differences in key responses from the

Table 1: Demographic Characteristics of Focus Group Participants

\begin{tabular}{|c|c|c|c|c|}
\hline & $\begin{array}{c}\text { Joint Medical } \\
\text { Program - } \\
\text { International } \\
(\mathrm{n}=6)\end{array}$ & $\begin{array}{l}\text { Bachelor of } \\
\text { Nursing - } \\
\text { International } \\
(n=10)\end{array}$ & $\begin{array}{c}\text { Master of } \\
\text { Pharmacy - } \\
\text { International } \\
(\mathrm{n}=8)\end{array}$ & $\begin{array}{c}\text { Local } \\
\text { Students } \\
(n=11)\end{array}$ \\
\hline Gender (Male/Female) & $2 / 4$ & $1 / 9$ & $5 / 3$ & $6 / 5$ \\
\hline Mean age & 21.6 & 27.7 & 24.6 & 22.0 \\
\hline Country of Origin & Malaysia 6 & $\begin{array}{c}\text { China } 5 \\
\text { Philippines } 2 \\
\text { Taiwan } 2 \\
\text { Saudi Arabia } \\
1\end{array}$ & $\begin{array}{c}\text { Malaysia - } 3 \\
\text { China - } 4 \\
\text { India - } 1\end{array}$ & Australia 11 \\
\hline Religion & $\begin{array}{c}\text { Muslim } 5 \\
\text { "Free thinker" } 1\end{array}$ & $\begin{array}{c}\text { Muslim } 2 \\
\text { Christian } 2 \\
\text { Buddhist } 1 \\
\text { No Religion } 5\end{array}$ & $\begin{array}{c}\text { Christian - } 1 \\
\text { Buddhist - } 2 \\
\text { Hindu - } 1 \\
\text { No Religion } \\
-3 \\
\text { Communist } \\
-1 \\
\end{array}$ & $\begin{array}{l}\text { Christian } 5 \\
\text { No religion } 6\end{array}$ \\
\hline
\end{tabular}


post-graduate (Pharmacy) and undergraduate (Nursing and Medicine) students.

The students fitted the pattern experienced nationally, with many medical students coming from high school in their home countries (particularly Malaysia) directly to medical schools in Australia. Other international students (particularly from other Asian countries) come first to English Language Intensive Courses for Overseas Students (ELICOS) before continuing on to university or other higher education. ${ }^{[19]}$

\section{Key Themes}

Focus group discussions with international students revealed several key themes: difficulties in spoken language; differences in professional roles and expectations; differences in methods of learning; inadequate social interaction outside the classroom; acceptance of differences in cultural and religious practices.

Language barriers. All international students had learned English previously, either in their country of origin or in Australia prior to their current degree. Despite this, they consistently reported language as a major barrier, and as the key to other difficulties faced ("everything is language barrier"). One student commented on the different sentence structure used and the "art of the language": I speak English but not Australian. It's difficult to make yourself understood and to understand Australian slang. All students agreed that speaking English and being understood in Australia was more difficult than they expected - they were assessed as being good at English in their country of origin but found it difficult to deal with "Australian English". One student explained that he was "maybe better than the teacher" in China but was struggling with communication in Australia. The pace of the conversation was also cited as a barrier to taking part in classroom and social discussions.

Generally, lecturers and tutors were described as communicating at a pace and using terminology that was appropriate and could be understood. Students reflected on early lectures as somewhat daunting and commented that some tutors spoke very quickly, but in general, comprehension in the learning context was improving.

Professional roles and expectations. All of the students had discovered that their profession is practiced quite differently in Australia compared to their countries of origin. Bachelor of Nursing students spoke predominantly about additional tasks such as assistance with feeding and bathing which are not regarded as part of the nurse's normal role in their home countries. The Australian practice of Medicine and Pharmacy was regarded as much more "patient-centered" or counselingfocused. Australian medical training emphasizes the emotional concerns of patients and takes a holistic view of health, whereas the students' view of medical practice and education in Malaysia placed a greater emphasis on scientific knowledge. The Malaysian medical students all preferred the Australian approach and indicated that they would like to continue this style of practice when they return to Malaysia. One student was concerned that she would need to "learn more to keep up with their [Malaysian doctor's] skills".

The Master of Pharmacy program has a major emphasis on counseling skills and interaction with patients. This varies greatly from the "business-centered" approach in China, India, and Malaysia. A Malaysian Master of Pharmacy student explained that in that country, pharmacy was a business with great emphasis on keeping the "customer" happy and making money - focus is given to learning product prices and bargaining. Students reported that China and India were also business-centered: "it is about getting more patients and dispensing them very fast." Interestingly, the more patientcentered approach was well-received by the students: "when you know that your job is being respected ... you get more job satisfaction and you like your job more and learn how to do it better". "In China, the Pharmacist is not very highly respected compared to doctor. It is the patient ['s] view that 'if I wanted counselling I would go to doctor - the Pharmacist doesn't know enough to make me feel better'. So they just take their medicine and leave, they treat Pharmacist[s] like sale[s] reps."

Although happy with the client-centered approach, some students acknowledged that the Australian approach may not be appropriate in their countries, and vice versa: "Each country has a different system. In Australia, this system works, and in China, that system works. When in Australia do it in the Australian way and when in China do that way." Patients in different countries have different expectations and do not want visits to the doctor or pharmacy to take so much time. "In Malaysia in retail Pharmacy it's fast pace. Patients don't want you to take your time and explain- they expect you to give them the script, tell them what they need to know, and leave. When you come here, if you practice the same style here it doesn't work." Also, the patient health professional relationship differs, such that health-professionals (particularly doctors) in many Asian countries are held in high esteem, with patients less likely to question the doctor's opinion or ask for further information - "they expect you to be a God,"

Different teaching and learning methods. A common theme in all programs, but possibly most pronounced amongst the Bachelor of Nursing students involved, was the different teaching style used here and the difficulty in understanding what is expected of them. In their countries of origin, these students were used to a much more didactic style of learning predominantly from a textbook. In Australia, and in particular at the University of Newcastle, health programs use a problem- 
based learning approach that relies on student interaction. Preparation was required before lectures and tutorials, and knowing what is expected were cited as difficulties. We are told "just ask" but we don't know what to ask. This was an obvious source of stress and frustration for the students.

Participation in small group tutorial sessions was a difficulty for all students, partly as a result of the pace of discussions and terminology used, and partly due to a discomfort with the style of participation. Several students commented that they had been initially surprised by the "lack of manners" displayed by students here. The students were used to addressing teachers as sir or madam, raising their hand when they wished to speak and having a far less interactive style of learning. While the interactive learning approach and more casual style of interaction with teachers was valued, the students did not feel comfortable interrupting or talking over others to take part in class discussions. Several students were shocked when they first saw local students with their "feet on chairs" in class and addressing tutors by their first name.

Social interaction with domestic students. Generally, international students reported being welcomed and supported by local students but finding difficulty in having genuine interactions outside of the university context. When asked about making Australian friends, several students commented that they had "Australian acquaintances, not friends" and all stated "we find ourselves making friends with people from our own country." These sentiments were reinforced in several discussions about the "cliques" that form in each student group, with Australianborn multicultural students, international students, and Australian students often forming separate friendship groups and retaining this structure in class situations.

There was a sense that after trying for the first few weeks to make friends with local students, it became easier to stay with the other international students for ease of communication and common understanding. While Australian students were reported to be friendly and welcoming, their topics of conversation (football and other sports, drinking alcohol on the weekend, politics) were foreign to the international students and they found it difficult to take part in conversation. Also, the speed of the conversations and slang terms used made it very difficult for the international students to follow. One student explained that while local students were very friendly towards her, because she has to translate English language discussion into her own language in order to understand, and then translate back again to respond, “...it takes time and they think [she is] an idiot."

Some social practices of Australian students also act as a barrier to inclusion. One student explained that he had been to some parties and social events but did not really feel part of it because "they weren't really sober." The drinking culture amongst Australian students may limit the extent to which some international students feel comfortable to take part.

Cultural and religious practices. Cultural practices and religious beliefs appeared to be less important than expected in contributing to the difficulties for international students. Generally, the international students, including the relatively conservative Muslim students, were very accepting of, and did not indicate any offense to, the dress or social customs displayed by their Australian peers. When asked about discussing sensitive issues such as sexuality in a professional context, the students indicated that they can easily treat such things from the clinical perspective and discuss them but may not be able to express empathy towards patients due to a lack of experience or a particular issue being against their personal or religious beliefs.

Socially though, the students did not appear to have any difficulty accepting differences. One Malaysian student commented about the Australian custom of shaking hands with patients: "This might be a problem for Muslim students. Its not a nationality issue but a religion issue. In KL its not that serious... nowadays we do shake hands."

The views of local students. In general, the domestic student views correlated with the comments from international students both in regard to social interaction and participation in class discussions. Domestic students cited trying to make friends but then finding that cliques had formed, and having "acquaintances" among the international students with whom they interacted at university but not often in social situations. They also reported international students often being "fairly quiet” during class discussions. Many local students were also interested to learn from the international students about their culture and religious beliefs.

These key themes can be viewed in terms of three different types of diversities identified in the educational setting: structural; informal interactional; and classroom. ${ }^{[20]}$ Given that international students and internationalization have become an integral part of tertiary education, structural diversity is already in place. It is imperative that this diversity is managed effectively - focusing on both informal and classroom diversity. The themes emerging from the present results can be used to generate recommendations for Academic staff [Table 2].

\section{Discussion}

Research with medical students in the United States, UK, and Australia has shown inequities in academic achievement between domestic and international or CALD students, especially in the increasingly used applied examinations such as the OSCE, or Objective Structured Clinical Examination. ${ }^{[21-24]}$ Students, themselves, recognize this gap in academic results 
Table 2: Recommendations for Institutions and Academic Stafi to Accommodate and Benefit from Diversity among Students

Informal interactional diversity

- Tertiary institutions should provide opportunities for socialization between local and International students such as shared, culturally safe events (considering dietary concerns, alcohol consumption, etc.).

- Institutions can provide opportunities for students from diverse backgrounds to share their culture with others through dedicated cultural awareness events. Classroom diversity

- Be aware of the pace of speaking in lectures and tutorials.

- Be aware of the use of slang terms and the nuances of spoken English - early sessions could include some explanation of commonly used terms.

- Encourage formation of mixed groups for tutorial activities.

- Provide preparatory materials for international students to help them understand the methods of learning that will be used, and understand their professional roles in their new context.

- Provide opportunities for students to enhance their English language proficiency through additional support and interaction with other students.

as well as opportunities for participation and involvement: "there's a big gap...huge gap between us and the local students." While international students are offered assistance and encouragement, there is a sense that more needs to be done to achieve equity. One Bachelor of Nursing student, expressing frustration with the difficulty of studying in a new style, in a new language, stated: "we are here to learn...I want people to understand that and help us...." This was a common feeling, particularly among Bachelor of Nursing and Master of Pharmacy students from diverse backgrounds, who are all very motivated to learn and succeed in their studies, but face great difficulty in doing so.

The results of this exploratory study support those reported in past research. ${ }^{[22-24]} \mathrm{A}$ series of studies focused on international students in tertiary education and in particular, medical schools, have described differences in these students' approach to learning and academic outcomes. ${ }^{[24]}$ Critical thinking skills, participation in tutorial discussion and depth of learning have been recognized as areas of weakness that are particularly challenging in health disciplines in which the learning style frequently calls for such skills. ${ }^{[24,25]}$ It has been questioned whether the collaborative, participatory model of communication in the medical interview and providerpatient consultations which is taught in most contemporary western universities are in fact suitable in cross-cultural interactions. ${ }^{[26]}$ International students have had difficulty learning these approaches, which differ from the approach traditionally used in their countries of origin, and are not expected, or desired by patients there. ${ }^{[26]}$ English language proficiency and difficulties in interacting with patients represent further barriers to academic and professional success for international students. ${ }^{[24,27]}$ Some medical schools ${ }^{[24]}$ and health programs ${ }^{[27]}$ have adopted specific health-related language and communication courses for their international students to help overcome these barriers.
This study has identified several key areas where efforts could be directed to help international students achieve equitable educational outcomes, and have a positive experience through their tertiary education in Australia and other English-speaking countries. The themes identified may be viewed as barriers to successful and enjoyable educational experiences for international students, but none of them is insurmountable. The themes largely relate to classroom diversity, and can be addressed in that context. Difficulties in spoken language, differences in professional roles and expectations and differences in methods of learning were uncovered here as the most significant barriers for international students. Each of these could be overcome through the provision of information or additional support to these students. Particularly, the latter two of these barriers could be dealt with by giving international students additional support in the form of preparatory materials or dedicated tutorials at the beginning of their study. Such tutorials could also be used to help international students practice and gain confidence in spoken English, and in particular discipline-specific language and slang terms which have been identified as major areas of difficulty. Academic staff members could also assist through an awareness of their pace of speaking in lectures and tutorials, and of their use of slang terms and other nuances of spoken English - early sessions could include some explanation of commonly used terms. Encouraging the formation of mixed groups for tutorial activities may increase opportunities for both classroom and informal interaction, with benefits for both international and local students.

Other themes identified relate more to informal interactional diversity and could be addressed at the wider institutional level. Culturally safe social events and opportunities for international students to share their culture (through dance, music, or food, rather than alcohol) could increase socialization. The results of the present exploration have led to a series of proposals to be implemented by the University of Newcastle. These recommendations are applicable to any similar tertiary education setting, particularly in health professional education.

At an international level, the appropriateness of this "Western" preparation for practice in a home country, and the potential for increasing global health inequity by educating and then retaining health professionals from developing countries, are ethical issues that should be addressed. Little or nothing is presently done to prepare current students for differences in practice in their home country. One of the main differences articulated by students is the more patriarchal style of communication in healthcare in their home country. While this is the current situation, there is an increasing trend towards a more participatory style of healthcare in Asia. ${ }^{[28]}$ One of the barriers to achieving this ideal is a lack of skills training in health professionals. ${ }^{[29]}$ Thus, the education received 
may be an advantage, rather than a disadvantage, enabling those students who have successfully gained these skills to be future professional leaders in their home countries. Some students arrive intending to stay in the host country, others decide to stay once they have qualified. The inequity caused by retaining these qualified health professionals in the host country when the need is great in their own country is a more complex issue and one that must be continually addressed by the global community.

There is a need for tertiary institutions that are benefitting economically from increasing numbers of international students to help them to study and live in a new environment. Assistance needs to go beyond learning the English language to helping students understand its use in a professional context (health terminology and slang used by patients), the nuances of the health professional disciplines in a western society, the approach to study and problem-based learning styles, and skills to assist with social interaction. The results of the present exploration have led to a series of proposed actions.

- Develop a curriculum for a short course to help international students gain an understanding of their professional roles in the Australian healthcare system, of the nuances of spoken English and slang terms used in the healthcare context, and of the approaches to teaching and learning in Australia.

- Increase opportunities for cultural understanding and socialization through formation of mixed groups within the classroom and for group assignment activities.

- Ensure that academic staff members are aware of the needs of CALD students and are equipped with skills to accommodate these needs through their course delivery.

Interestingly, it seems that rather than major changes to existing curricula in health programs or courses, the addition of a preparatory curriculum for international students would help to overcome many of the difficulties faced. There is an opportunity for local students and academic staff to benefit from international students in expanding our understanding of patient needs and expectations. Effective collaboration with international students may represent a useful strategy for teaching about intercultural interactions.

\section{References}

1. Australian Government Department of Employment Education, and Workplace Relations (DEEWR). DEEWR student dataset. Canberra: Commonwealth of Australia; 2011. Available from: http:// www.deewr.gov.au/HigherEducation/Publications/HEStatistics/ Publications/Pages/Students.aspx. [Last cited in 2012 Feb 10].

2. Institute of International Education. Open Doors Data. 2011. Available from: http://www.iie.org/Research-and-Publications/ Open-Doors/Data. [Last cited in 2012 Feb 10].

3. UK council for International Student Affairs. International students in UK higher education: Key statistics. 2011. Available from: http:// www.ukcisa.org.uk/about/statistics_he.php. [Last cited in 2012 Feb $10]$.

4. Birrell R, Hawthorne L. Immigrants and the professions in Australia. Melbourne: Monash University; 1997.

5. Re: New AEI, A discussion starter. Canberra: Australian Government, Australian Education International; 2010.

6. Saha S, Guiton G, Wimmers PF, Wilkerson L. Student body racial and ethnic composition and diversity-related outcomes in US medical schools. JAMA 2008;300:1135-45.

7. Gilchrist KL, Rector C. Can you keep them? Strategies to attract and retain nursing students from diverse populations: Best practices in nursing education. Journal of Transcultural Nursing 2007;18:277-85.

8. Labun E. The red river college model: Enhancing success of native Canadian and other nursing students from disenfranchised groups. Journal of Transcultural Nursing 2002;13:311-7.

9. Stewart B. Enhancing success in BSN nursing education for minority nurses. ABNF J 2005;16:8-10.

10. Sutherland JA, Hamilton MJ, Goodman N. Affirming At-Risk Minorities for Success (ARMS): Retention, graduation, and success on the NCLEX-RN. Journal of Nursing Education 2007;46:347-53.

11. Guhde JA. English-as-a-second language (ESL) nursing students: Strategies for building verbal and written language skills. Journal of Cultural Diversity 2003;10:113-7.

12. Arkoudis S, Hawthorne L, Baik C, Hawthorne G, O’Loughlin $\mathrm{K}$, Leach $\mathrm{D}$, et al. The impact of English language proficiency and workplace readiness on the employment outcomes of tertiary international students. Melbourne: Centre for the Study of Higher Education (CSHE) and the Faculty of Medicine, Dentistry and Health Sciences (MDHS) of the University of Melbourne; 2009.

13. Examples of good practice in assisting international students to integrate with Australian students and the wider community. Canberra: Australian Government Department of Education, Employment, and Workplace Relations; 2009.

14. Treloar C, McCall N, Rolfe I, Pearson SA, Garvey G, Heathcote A. Factors affecting progress of Australian and international students in a problem-based learning medical course. Medical Education 2000;34: 708-15.

15. Kuteyi O, McLean A, Carr S, Danh C, Saplontai D, Shiao S. How does the learning experience of international and domestic medical students relate to their health, wellbeing and self rated performance? Focus on health professional education. Focus on Health Professional Education: A Multi-Disciplinary Journal 2009;11:22-31.

16. Hamilton J. The collaborative model of doctor-patient consultation. Is it always culturally appropriate? What do doctors and patients need to know to make it work in intercultural contexts. Medical Teacher 2009;31:862-5.

17. Malterud K. Shared understanding of the qualitative research process. Guidelines for the medical researcher. Family Practitioner 1993;10:201-6.

18. Frich JC, Hoye S, Lindbaek M, Straand J. General practitioners and tutors' experiences with peer group academic detailing: A qualitative study. BMC Family Practice 2010;11:2.

19. Study pathways of international students in Australia. Australian Government. Contract No.: 2008/01. Canberra: Australian Education International; 2008.

20. Nkansah NT, Youmans SL, Agness CF, Assemi M. Fostering and managing diversity in schools of pharmacy. American Journal of Pharmaceutical Education 2009;73:152.

21. Wass V, Roberts C, Hoogenboom R, Jones R, Van der Vleuten C. Effect of ethnicity on performance in a final objective structured clinical examination: Qualitative and quantitative study. British Medical Journal 2003;326:800-3. 
22. Fernandez A, Wang F, Braveman M, Finkas LK, Hauer KE. Impact of student ethnicity and primary childhood language on communication skill assessment in a clinical performance examination. Journal of General Internal Medicine 2007;22:1155-60.

23. Woolf K, Potts HW, McManus IC. Ethnicity and academic performance in UK trained doctors and medical students: Systematic review and meta-analysis. British Medical Journal 2011;342:1-14.

24. Hawthorne L, Minas IH, Singh B. A case study in the globalization of medical education: Assisting overseas-born students at the University of Melbourne. Medical Teacher 2004;26:150-9.

25. Renshaw P, Volet S. South East Asian students at Australian universities: A reappraisal of their tutorial participation and approaches to study. Australian Education Research 1995;22: 85-106.

26. Hamilton J. The collaborative model of doctor-patient consultation-is it always culturally appropriate? What do doctors and patients need to know to make it work in intercultural contexts? Medical
Teacher 2009;31:163-5.

27. Graham JG, Beardsley RS. English for specific purposes: Content, language, and communication in a pharmacy course model. Tesol Quarterly 1986;20:227-45.

28. Finset A, Visser A. Asian perspectives on patient education and health care communication. Patient Education Counselling 2011;85:335.

29. Claramita M, Utarini A, Soebono H, Van Dalen J, Van der Vleuten C. Doctor-patient communication in a Southeast Asian setting: The conflict between ideal and reality. Advanced Health Science Education Theory Practice 2011;16:69-80.

How to cite this article: Citation will be included before issue gets online ${ }^{\star * *}$

Source of Support: Nil. Conflict of Interest: None declared.

Author queries???

AQ6: Journal abbreviation not found in PubMed. Kindly provide???

AQ8: Please confirm correspondence address??? 